\title{
BIO-DIVERSITY IN NEEM (AZADIRACHTA NDICA A. JUSS) WITH SPECIAL EMPHASIS ON SEED YIELD PARAMETERS.
}

\author{
${ }^{*} N$. Srividya and ${ }^{*} B$. Poorna Sri Devi
}

Azadirachta indica A. Juss, commonly known as neem has been indicated to have high species, intraspecific and ecological diversity. Attributed with many wondrous properties, neem has generated a worldwide scientific interest. Among the various seed yield parameters, hundred seed weight has been found to serve as a reliable selection index in neem. Since neem seeds are the important source of several valuable phytochemicals, selection of elite trees with high seed yield becomes imperative. Seed and leaf materials of thirteen accessions of neem were collected from different edaphic and agroclimatic regions of Anantapur district in the state of Andhra Pradesh. To assess the biodiversity, 16 morphological characters of seeds and leaves were scored. This included leaf qualitative traits (lamina colour \& taste, depth \& regularity of serration, serration tip pointedness, emergence of mid-vein, venation pattern) and quantitative traits of leaf (lamina length \& breadth, leaf length, number of leaflets/leaf, number of serrations) and seed (length, breadth, L/B ratio, 100 seed weight). The above parameters were subjected to extensive statistical analysis. Individual leaf qualitative traits revealed moderate degree of variation among the accessions studied. Bio-diversity in independent quantitative traits was revealed by the values of co-efficient of variation (CV). The $\mathrm{CV}$ ranged from $14 \%$ for number of leaflets/leaf to $33 \%$ for number of serrations

- Deparment of Home Science, Sri Sathya Sai Institute of Higher Learning, Anantapur - 515001

- Deparment of Botany, Sri Sathya Sai Institute of Higher Leaming, Anantapur - 515001 
among the leaf parameters. For the seed parameters, the $\mathrm{CV}$ ranged from $7 \%$ for seed length to $20 \%$ for 100 seed weight. Polygonal analysis using multiple traits divided the 13 accessions into 7 groups indicating the existence of bio-divergence in neem. Multiple correlation analysis carried out revealed significant correlation of the important seed yield parameter, 100 seed weight with- seed breadth $(r=0.71$ at $p<0.01)$, seed length $(r=0.54$ at $p<0.05)$, leat length $(r=0.48$ at $p<0.05)$, and serration pointedness $(r=-0.72$ at $p<0.01)$. The important contribution of this investigation is the identification of simple visual marker for selecting elite trees with good seed yield. Early and year round selection of elite varieties is possible using leaf length and serration pointedness, well before the production of seeds begin.

Key Words: Neem, bio-diversity, seed yield parameters, visual markers.

\section{Introduction}

NEEM (Azadirachta itu\&ca A. Juss), the multi-purpose wonder tree of the tropics has emerged as a suitable candidate to meet the demands for environmentally benign pest control agents, safe medicinals besides wood and non-wood products. The importance of neem is increasing worldwide and the growth of neem market is envisaged.

Neem has been indicated to have high species, intraspecific and ecological diversity and to show genetic variation (Dogra and Thapliyal, 1993) due to its highly crosspollinated nature (Singh et al., 1996) and wide distribution range. Knowledge of genetic variability of concerned species becomes essential for initiating a rational tree-improvement program. Therefore, it is mandatory to evaluate and characterize the gcrmplasm/acccssions for sustainable utilization. The characterization can be achieved through morphological, cytological, biochemical or molecular markers. This would help provide useful information about the diversity and utility of the germplasm in terms of valuable characters of important raw material such as fruit and seed, production of foliage, oil, active ingredients etc. Only recently, few institutions have initiated systematic germplasm collection and provenance work in neem. The Department of Science and Technology (DST) have also recommended the documentation of neem germplasm using morphological features and DNA markers (TIFAC, 1996).

Since seeds are the concentrated source of important neem phytochemicals, the total yield will depend on both the seed content and seed yield of a tree. Thus, seed yield related parameter needs to be considered when selecting trees. Fruit weight 
has been reported to have positive association with fruit yield (Vir and Jindal, 1999). This suggests seed weight to be a good indicator of seed yield. Hundred seed weight has also been reported (Kumaran ef al., 1996) to be a reliable selection index by virtue of its high geno-typic co-efficient of variance, high genetic advance, and moderate heritability in comparison to few other seed parameters analyzed. For the above reasons, hundred seed weight becomes an important parameter, which needs evaluation before selecting trees for breeding/improvement programs or for commercial exploitation.

The present study, thus, focussed on determining the extent of bio-diversity in neem and on identifying simple morphological marker(s) for hundred seed weight, an essential seed yield parameter.

\section{Materials and methods}

Seed and leaf materials of thirteen accessions of neem collected Prom the different regions of Anantapur district (Andhra Pradesh) were scored for sixfeen morphological characters, which included 7 qualitative and 9 quantitative characters. The morphological characters scored are listed below.

\section{Qualitative Characters}

i) Pattern of venation

ii) Pattern of emergence of midvein

iii) Lamina colour

iv) Lamina taste

v) Regularity of serration

vi) Depth of the serration

vii) Pointcdncss of serration tip.

\section{Quantitative Characters}

i) Leaflength ( $\mathrm{cms}$ )

ii) Lamina length ( $\mathrm{cms}$ )

iii) Lamina breadth ( $\mathrm{cms}$ )

iv) Number of leaflets/ leaf

v) Number of serrations in the lower margin of lamina

vi) Seed length (cms)

vii) Seed breadth (cms)

viii) Seed length/breadth ratio

ix) Hundred seed weight (g)

The 13 accessions were collected from four provenances. Five accessions (code: PUTI, PUT2, PUT3, PUT4, PUT5) were selected from Puttaparty provenance. Three accessions each were selected from Meluvoi (ME1, ME2, ME3) and Madakasira (MAl, MA2, MA3) provenances. Two accessions (ATP1, ATP2) were studied Prom Anantapur provenance. 
Morphometric analyses of the morphological features scored were carried out using various statistical methods (Gupta, 1991; Statgraphics, 1986). Depending upon the type of data, suitable measures of variation were used to assess the divergence exhibited by individual characters among the different accessions and study areas. They include mean \pm standard deviation (SD), range and co-efficient of variation (CV). Polygon method, a simple graphic procedure (Davidson, 1947, and Rao, 1979) which helps in simultaneous portrayal of several variables was chosen to illustrate the variation among the 13 accessions studied based on many traits. Each radius of the polygon represents a single character and the distance from the centre along it expresses the variation of that character. The shape and size of the polygons are 2 parameters of comparison to obtain the degree of similarity or dissimilarity among the populations represented. Polygonal graphs for each of the 13 neem germplasm/accessions were drawn separately for 9 quantitative and 7 qualitative parameters. Multiple correlation analysis using Karl Pearson's method for quantifative parameters, Hul Spearman's Rank correlation method (Gupta, 1991 and Stalgraphics, 1986) for the qualitative parameters were carried out to determine correlation between these parameters and the important seed yield parameter of 100 seed weight.

\section{Results and Discussion}

The different accessions of neem were first grouped based on the leaf qualitative morphological characters. Each character was scored in three grades except serration tip. The grouping is presented in table-1. It can be observed from the table that for each character the grouping of the accessions is different Earlier studies have not documented these qualitative traits. However, the drawings presented by Schmutterer(1995) of varying leaf morphology exhibited the difference in the pattern of mid-vein emergence as observed in the present study.

Among the quantitative leaf character! ${ }^{*}$ leaf length showed a variation from 19.6 to $31 \mathrm{~cm}$. TewHri (1992) and Mohan Ram and Nair (1993) also observed similar variation in leaf length from 20 to $40 \mathrm{~cm}$. In the present study, the number of leaflets/leaf ranged from 11 to 18 per leaf. Similar observations were made by Tewari (1992) (9 to 13) and Mohan Ram and Nair (1993) (8 to 19) in neem. Leaflet lamina length scored among the neem accessions varied from 5.6 to $9.7 \mathrm{~cm}$ and the same was reported earlier by the above mentioned authors and the values ranged between 2 and $8 \mathrm{~cm}$. The range of lamina breadth was observed to be 1.37 to $3.10 \mathrm{~cm}$ and was found to be comparable to the values $(1.2-4.0 \mathrm{~cm})$ reported by Tewari (1992). Regarding the number of serrations on the lower margin of leaflets, a variation of 2.72 to 6.84 was noticed. No such reports are available on 
this aspect. Variation observed in the present study might be due to the environmental or genetic factors.

Co-efficient of variation (CV\%) whs calculated as an indicator of variability (lable2). The present investigation has indicated highest variability for number of serrations in the lower margin of lamina of the leaflet (32.39\%), which ranged from 13.56 to $54.79 \%$ CV among the different provenances. The lowest average CV (14\%) was recorded for number of leaflets per leaf.

From the above account it is clear that the accessions under investigation exhibited wide variation in their leaf qualitative and quantitative characters irrespective of the provenances.

Regarding seed morphology, an overall variability of 1.19 to $1.60 \mathrm{~cm}$ for seed length and 0.5 to $0.74 \mathrm{~cm}$ for seed width was observed. This is comparable to that reported by Veerendra (1995), who observed the seed length to vary from 1.1 to $1.8 \mathrm{~cm}$ and seed breadth from 0.45 to $0.85 \mathrm{~cm}$. For 100 seed weight the earlier study has, reported a wider range $(100$ to $530 \mathrm{mg})$ than observed in the present study (158 to $321 \mathrm{mg}$ ). This could be because of more number of accessions and provenances included in the earlier study. Variation in seed $\mathrm{L} / \mathrm{B}$ ratio has been also recorded by Kumaran et al, (1996) among 28 accessions from Tamil Nadu.

The co-efficient of variation computed for seed traits are presented in table-3. The highest $\mathrm{CV}$ recorded for seed length, seed width and 100 seed weight for samples from four provenances in the present study were $16.3 \%, 22.1 \%$ and $48.38 \%$ respectively, while that reported by Veerendra (1995) were $9.1 \%, 10.5 \%$ and 24.0 $\%$ respectively. Among the seed parameters, highest variability has been observed for 100 seed weight in the present investigation and also has been reported by Veerendra (1995). The high variability for 100 seed weight, an important seed yield related parameter suggests that this could be exploited for increasing seed weight/ yield by appropriate selection and breeding methodology.

The polygonal study based on seed and leaf quantitative traits of the thirteen-neem accessions from four different provenances of Anantapur district aided in splitting them into 7 different groups (Fig. 1) as follows: Group (A) MEI, ME2, ME3 and MAl ; (B) MA2, MA3, PUT3 ; (C) PUT1 ; (D) PUT2, PUT5 ; (H) PUT4 ; (F) Al A2.

Polygonal graphs drawn using the seven qualitative characters also indicated a high level of variation among (he accessions studied (Fig.2). N《) similarity was observed among accessions within each provenance. However, when all the accessions were considered together, moderate degree of similarity whs discerned 
only for four pairs of accessions - ME2 and A2, ME3 and MA2, MAl and Al, and $M A 3$ and PUTI, except for few characters like mid-vein emergence, lamina colour and serration patterns.

Qualitative parameters, such as serration characters of leaflets and mid-vein emergence patterns, expected to be affected least by environmental factors have also shown high variability among the accessions substantiating the existence of genetic divergence and a broad genetic base. Earlier studies have also reported variation among neem accessions of different countries (Kundu, 1999) and different regions of India (Singh et al., 1999).

Such a genetic divergence observed in the present study has been also reported in other studies using molecular markers. Molecular analysis based on AFLP (Amplified fragment length polymorphism) markers in 37 neem accessions from different ecogeographic regions of India (Singh et at, 1999) showed absence of similar DNA profile between any two accessions indicating each accession to be unique. Such molecular studies, if coupled with morphological and chemical studies, would be interesting and could help bring out the genetic basis behind the variation of these traits.

Multiple correlation analysis revealed hundred seed weight to show positive correlation with leaf length $(r=0.48)$ and seed length $(r=0.54)$ at $90 \%$ confidence level. It however, exhibited highly significant (PO.01) correlation with seed breadth ( $\mathrm{r}$ $0.71)$. Hundred seed weight also showed strong negative correlation with serrationpointedness $(r=0.72)$ at $99 \%$ (PO.01) confidence level.

Seed length and width could be used to select seed lots initially by visual observation before confirming through measurements. Since, seed production is seasonal in neem; the leaf morphological markers identified (serration pointedness and leaf length) in the present study become valuable for year-round assessment of seed weight, making selection season-independent. Another additional advantage is that trees in a plantation/those growing wild could be marked out for high seed yield much before the fruit production begins in neem trees which generally takes about $S-6$ years. Those with predicted lesser yield could be thus utilized for other end uses such as for timber, poles, leaf fodder, nccm cake production etc.

\section{Conclusion}

The present investigation has, thus, revealed variation among germplasm obtained from a smaller region in India, indicating high intraspecific variability in neem. Further, the study has helped identify simple morphological markers for hundred 
seed weight, an important seed yield related parameter. Analysis on a larger sample size and in trees growing in a plantation and other eco-systems could help further evaluate and confirm the usefulness as simple morphological markers identified.

Table-1 Grouping of the Accessions into Different Character - States (Qualitative Characters)

\begin{tabular}{|c|c|c|c|}
\hline S.No. & Characters & States & Accessions \\
\hline 1) & Lamina Colour & $\begin{array}{l}\text { Light green } \\
\text { Green } \\
\text { Dark Green }\end{array}$ & $\begin{array}{l}\text { ME2, MA3, A2, ME3, MAI, } \\
\text { MA2, PUT1, PUT3, PUT4 } \\
\text { ME1, PUT2, Al, PUT5 }\end{array}$ \\
\hline 2) & $\begin{array}{l}\text { Lamina Taste } \\
\text { (Degree of Bitterness) }\end{array}$ & $\begin{array}{l}\text { Low } \\
\text { Medium } \\
\text { High }\end{array}$ & $\begin{array}{l}\text { PUT1, PUT4 ME2, MA3, } \\
\text { PUT2, PUT3, A2, PUT5 ME1, } \\
\text { ME3, MAl, MA2, Al }\end{array}$ \\
\hline 3) & Venation & $\begin{array}{l}\text { Not conspicous } \\
\text { Slightly conspicous } \\
\text { Conspicous }\end{array}$ & $\begin{array}{l}\text { MAl, MA2, Al ME1, MA3, } \\
\text { PUT1, PUT2, PUT5 ME2, } \\
\text { ME3, PUT3, PUT4, A2 }\end{array}$ \\
\hline 4) & Emergence of Mid-Vein & $\begin{array}{l}\text { Smooth } \\
\text { Slightly Curved } \\
\text { Curved }\end{array}$ & $\begin{array}{l}\text { PUT2, PUT3, PUT4, A2, PUT5 } \\
\text { ME1, ME3, MA2, PUT1 ME2, } \\
\text { MAI, MA3, Al }\end{array}$ \\
\hline 5) & Serration Regularity & $\begin{array}{l}\text { Irregular } \\
\text { Moderately regular } \\
\text { Regular }\end{array}$ & $\begin{array}{l}\text { ME2, PUT2, PUT4, Al } \\
\text { ME3, MA2, A2,PUT5 ME1, } \\
\text { MAI, MA3, PUT1, PUT3 }\end{array}$ \\
\hline 6) & Serration Depth & $\begin{array}{l}\text { Shallow } \\
\text { Slightly deep } \\
\text { Deep }\end{array}$ & $\begin{array}{l}\text { ME1, ME2, ME3, PUT3, Al } \\
\text { MAl, MA2, A2 MA3, PUT1, } \\
\text { PUT2, PUT4, PUT5 }\end{array}$ \\
\hline 7) & Serration Tip & $\begin{array}{l}\text { Blunt } \\
\text { Pointed }\end{array}$ & $\begin{array}{l}\text { MAI, PUT3, PUT4, Al ME1, } \\
\text { ME2, ME3, MA2, MA3, } \\
\text { PUT1, PUT2, A2, PUT5 }\end{array}$ \\
\hline
\end{tabular}




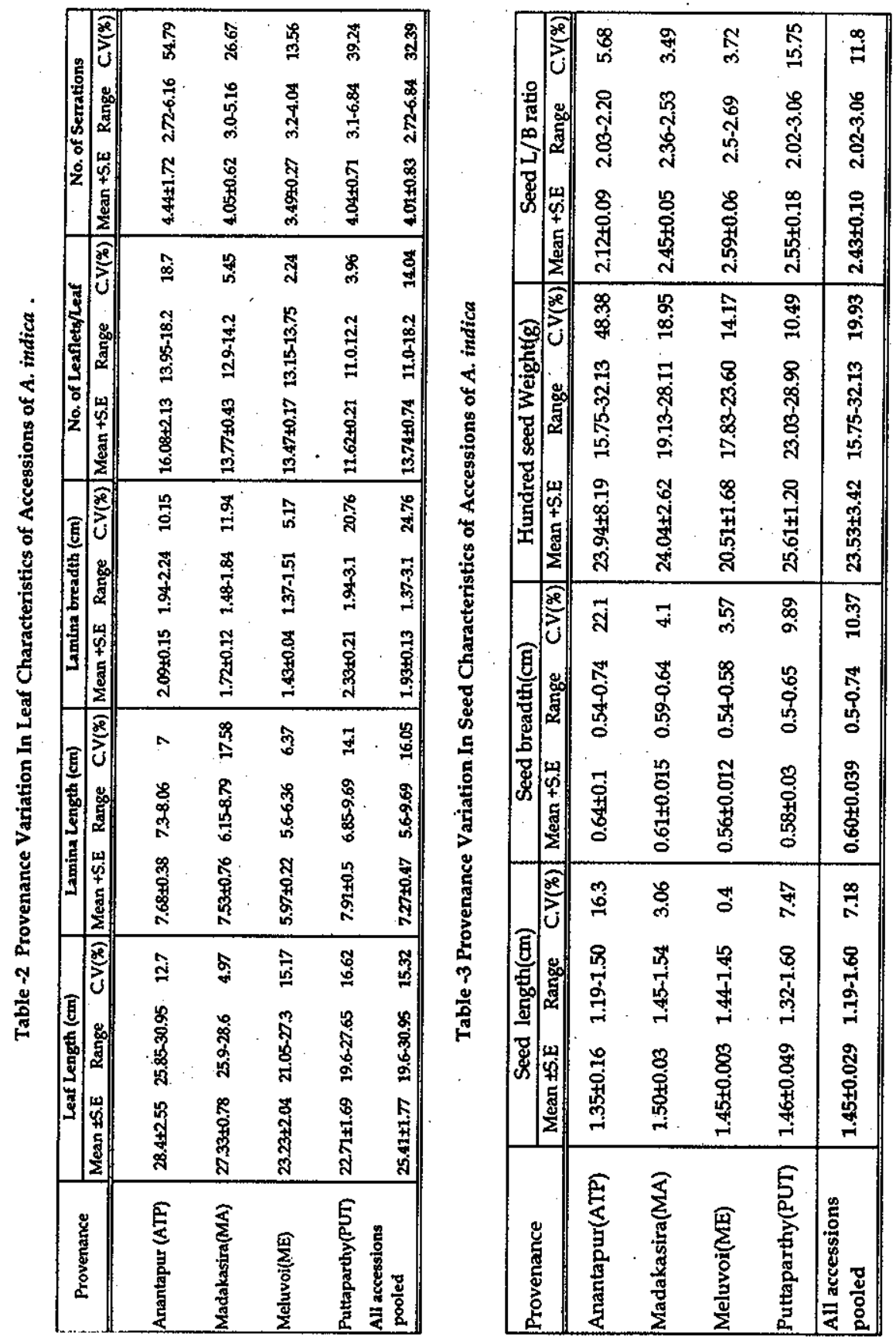


Figure.1 Polygons of neem accession $(9$ quantitative traits)
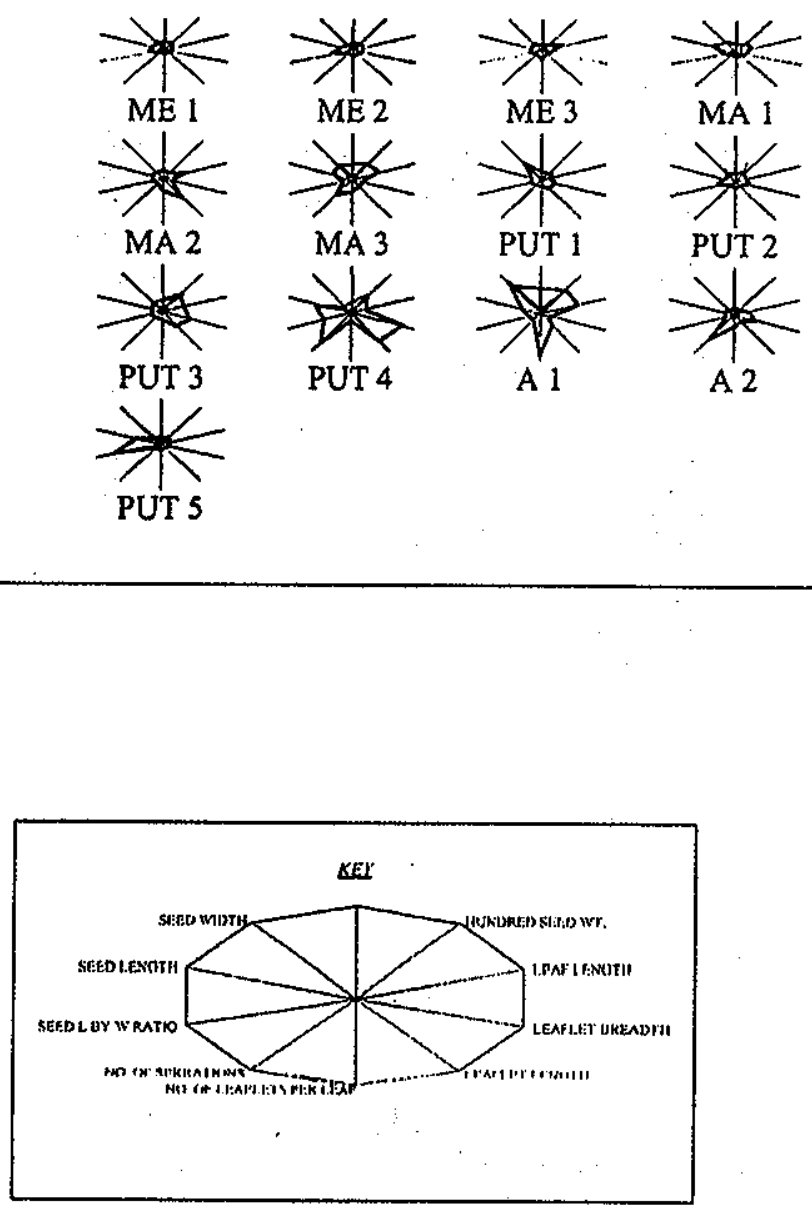
Figure. 2 Polygonal graphs of Neem accessions (Qualitative Data)

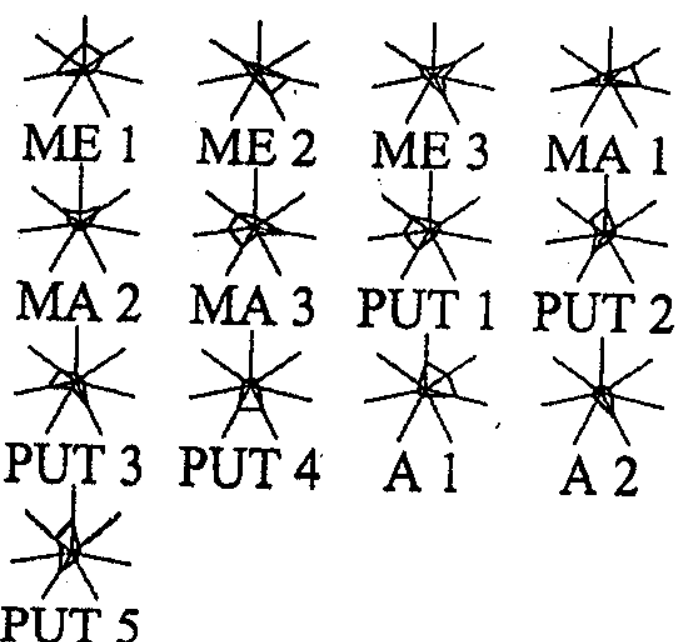

Key

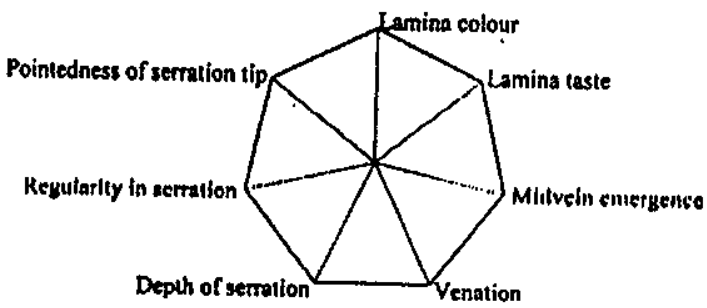




\section{References}

1 Davidson, J.F. (1947) The polygonal graph for simultaneous portrayal of several variables in population analysis. Modrono. 9: 105-110.

2 Dogra, P.D. and Thopliyal, R.C. (1993) Gene resources and breeding potential. In. Neem Research and Development, Publication No.3, (Eds.) N.S. Randhawa and B.S. Parmar, Society of Pesticide Science, India, pp.27-32.

3 Gupta, S.P. (1991) Statistical Methods. Sultan Chand and Sons Publ, New Delhi - 2.

4 Kumaran, K., Surendran, C. and Rai, R.S.V. (1996a) Variation studies and heritable components of seed parameters in neem. In : Neem and Environment, VolJ (Eds.) R.P., Singh, M.S.,Chari, A.K.,Raheja and W.Kraus, Oxford and TBH Publishing Co., Pvt., Ltd., New Delhi, pp. 167-172.

5 Kundu, K.S.(1999) Comparative analysis of seed morphometric and alioyme data among four populations of neem (Azadirachto indica). World Neem Conference, 19-21 May, University of British Columbia, Vancouver, Canada. Abstr. No.C-3-2.

6 Mohan Ram, H.Y. and Nair, M.N.B. (1993) Botany. In: Neem Research and Development, (Eds.) N.S. Randhawa and B.S. Pormar, Publication No.3, Society of Pesticide Science, India, pp.6-26.

7 Rao, C.K. (1979) Morphological, cytological and chemosystematic studies of some Indion Golegare (Foboceae). PhD. thesis, Andhra University, Waltair, AP.

8 Schmutterer, H. (1995) The Neem Tree, Azadirachto indica A Juss. And Other Melioceous Plants - Sources of Unique Natural Products for Integrated Pest Management, Medicine, Industry and other Purposes. VCH Publishers inc., Weinheim (FRG) and New York (USA).

9 Statgraphics® Plus - Version 3.1 (Statistical Software Package). Statistical Graphics Corp. U.S. 1986.

10 Singh, V.P., Dhillon, R.S. and Jhorar, B.S. (1996) Floral biology, breeding behaviour and breeding strategy in neem (Azadirochto indica A Juss). World Neem Conf,, 4-9 February, Gatton College, Australia, Abstr. P.61.

11 Singh, A, Negi, M.S., Rajagopal, J., Bhatia, S., I'omar, U.K., Srivastava, P.S. and Lakshmikumaran, M. (1999) Assessment of genetic diversity in Azadirachto indica using AFLP markers. Theor. Appl Genet, $99: 272-279$.

12 Tewari, D.N. (1992) Monograph on neem (Azadirachta indica A Juss). International Book Distributions, Dehra Dun, India.

13 TIFAC (1996) Life Sciences and Biotechnology : Technology Vision - 2020. Technology information, forecasting and assessment council, DST, New Delhi, p. 5.

14 Veerendra, H.C. S(1995) Variation studies in provenances of Azadirachto indica (the neem tree). Indian Forester, 121 (11): 1053-56.

15 Vir, S. and Jindal, S.K. (1999) Improvement of nccm for seed yield, oil content and pesticidal uses. World Neem Conference, 19-21 May, University of British Columbia, Vancouver, Conada, Abstr.No.P-13. 